\title{
Concerns re: interpretation and translation of findings in Energy use, blue water footprint, and greenhouse gas emissions for current food consumption patterns and dietary recommendations in the US
}

\author{
Brent F. Kim ${ }^{1,2} \cdot$ Keeve E. Nachman ${ }^{1,2,3,4}$ - Roni A. Neff ${ }^{1,2,3}$ - Marie L. Spiker ${ }^{1,5}$. \\ Raychel E. Santo ${ }^{1,6}$
}

Published online: 16 February 2016

(C) Springer Science+Business Media New York 2016

Tom, Fischbeck, and Hendrickson of Carnegie Mellon University (CMU) performed a valuable analysis of the energy use, blue water footprint, and greenhouse gas (GHG) emissions associated with typical diets in the USA, reduced calorie diets, and diets matched to the Dietary Guidelines for Americans (Tom et al. 2015).

We have two concerns regarding the study and its translation, primarily as they apply to the climate impact of dietary shifts. First, the authors' interpretation of their results in relation to reduced meat consumption, both in their article and to a greater degree in CMU's press release (Rea 2015), extrapolates beyond what the study methods can support. Second, in the press release, the authors present an extreme and unrealistic comparison to suggest that a shift to more plant-centric diets may increase greenhouse gas emissions-a message that misrepresents the study

Brent F. Kim

bkim40@jhu.edu

1 Johns Hopkins Center for a Livable Future, Johns Hopkins University, Baltimore, MD, USA

2 Department of Environmental Health Sciences, Johns Hopkins Bloomberg School of Public Health, Baltimore, MD, USA

3 Department of Health Policy and Management, Johns Hopkins Bloomberg School of Public Health, Baltimore, MD, USA

4 Johns Hopkins Risk Sciences and Public Policy Institute, Johns Hopkins Bloomberg School of Public Health, Baltimore, MD, USA

5 Department of International Health, Johns Hopkins Bloomberg School of Public Health, Baltimore, MD, USA

6 School of Planning and Geography, Cardiff University, Cardiff, Wales, UK findings and prior evidence on dietary contributions to climate change.

In their discussion, Tom et al. note that "the environmental benefits of reduced meat consumption may be offset by increased consumption of other relatively high impact foods, thereby challenging the notion that reducing meat consumption automatically reduces the environmental footprints of one's diet." We agree with this assessment and believe it is an important consideration, particularly as it applies to substituting meat with large amounts of dairy-a GHG emissions-intensive food group, in some cases even more so than pork and poultry when comparing emissions per serving (Tilman and Clark 2014).

That said, the study is not well suited to demonstrate the impacts of reducing meat intake because the scenario analyzed did not simply reduce meat consumption and replace it with an equivalent amount of non-meat alternatives. Rather, added sugars, solid fats, and oils (lowemissions food groups) were reduced, while meat from aquatic animals (a high-emissions food group) was increased. These shifts are intended to measure the effects of adopting Dietary Guidelines for Americans-a timely and thoughtful analysis-but change too many variables for isolating the effects of reducing meat consumption.

The press release further extrapolates from the findings to suggest that "vegetarian diets... could be more harmful to the environment." Just as the study was not designed to assess reduced meat consumption, it did not assess vegetarian diets. Terrestrial meat intake was reduced but not eliminated, fish and seafood intake increased, and as above, too many variables were changed to isolate the effects of eliminating meat consumption. Although the data presented in Fig. 2 suggest that some plant-based foodsparticularly fruits and vegetables-require greater blue water and energy use than meat, these impacts are 
compared per calorie, a metric that presents calorie-dense foods in a more favorable light.

In the press release, the authors illustrate an extreme case of a misleading per-calorie comparison by describing lettuce as "three times worse in greenhouse gas emissions" than bacon. Given that bacon and lettuce have drastically different caloric densities (4.68 and $0.15 \mathrm{kcal} / \mathrm{g}$, respectively) (USDA 2015), a person would need to eat 22 cups of lettuce to match the calories in two slices of bacon. This comparison makes for an attractive headline, but relies on unrealistic assumptions about dietary substitutions.

In contrast to the implications made in the interpretation and translation of their findings, Tom et al. found red meat and seafood to be by far the most GHG emissions-intensive food groups. Based on a visual assessment of Fig. 2, red meat was at least 4.5 and 30 times more emissions intensive than vegetables and grains, respectively, even when comparing emissions per calorie. Tilman and Clark (2014) similarly found plant-based foods to have dramatically lower emissions intensities than ruminant meat, seafood, pork, and poultry, whether the denominator is calories, servings, or-in the case of grains, roots, and legumesgrams of protein. These findings are consistent with evidence suggesting plant-based diets (Stehfest et al. 2009), vegetarian diets (Stehfest et al. 2009; Tilman and Clark 2014), reduced meat intake (Stehfest et al. 2009; Popp et al. 2010; Hedenus et al. 2014; Tilman and Clark 2014) and reduced meat and dairy intake (Stehfest et al. 2009; Bajželj et al. 2014; Hedenus et al. 2014) could substantially reduce GHG emissions.

Taken together, the interpretation and translation of Tom et al.'s findings mischaracterize the original study and prior evidence on the climate impact of meat production. The press release goes on to rebut remarks made at the Paris COP21 climate conference about the importance of reducing meat intake. These messages were then disseminated by various media outlets (e.g., Dowd 2015; Patterson 2016).

A strong body of evidence suggests immediate and substantial reductions in meat and dairy intake are critical to meeting climate mitigation targets (Bajželj et al. 2014; Hedenus et al. 2014; Kim et al. 2015). Achieving this goal will require a global shift toward more plant-centric diets, particularly in countries such as the USA with high per capita animal product consumption (FAO 2013). In the USA, there is considerable political opposition to addressing climate change, and strong cultural barriers to reducing meat consumption. Sending a message indicating meat may be a preferable food choice, without adequate supporting evidence, runs counter to climate mitigation efforts and the best interests of future generations.

\section{References}

Bajželj B, Richards KS, Allwood JM et al (2014) Importance of fooddemand management for climate mitigation. Nat Clim Change 4:924-929. doi:10.1038/nclimate2353

Dowd K (2015) Lettuce "three times worse" for environment than bacon, new study says. In: SFGate. http://www.sfgate.com/ science/article/Lettuce-worse-than-bacon-for-environment-6699 787.php. Accessed 11 Jan 2016

Hedenus F, Wirsenius S, Johansson DJA (2014) The importance of reduced meat and dairy consumption for meeting stringent climate change targets. Clim Change 124:79-91. doi:10.1007/ s10584-014-1104-5

Kim B, Neff R, Santo R, Vigorito J (2015) The importance of reducing animal product consumption and wasted food in mitigating catastrophic climate change. Johns Hopkins Center for a Livable Future. http://www.jhsph.edu/research/centers-andinstitutes/johns-hopkins-center-for-a-livable-future/research/clf_ publications/pub_rep_desc/the-importance-of-reducing-animalproduct-consumption-and-wasted-food-in-mitigating-catastrophicclimate-change.html

Patterson B (2016) Lettuce produces more greenhouse gas emissions than bacon does: a vegetarian diet does not necessarily have a low impact on the environment. In: Scientific American. http:// www.scientificamerican.com/article/lettuce-produces-more-green house-gas-emissions-than-bacon-does/. Accessed 11 Jan 2016

Popp A, Lotze-Campen H, Bodirsky B (2010) Food consumption, diet shifts and associated non- $\mathrm{CO}_{2}$ greenhouse gases from agricultural production. Glob Environ Change 20:451-462. doi:10. 1016/j.gloenvcha.2010.02.001

Rea S (2015) Vegetarian and "Healthy" diets could be more harmful to the environment. In: Carnegie Mellon University News. http:// www.cmu.edu/news/stories/archives/2015/december/diet-andenvironment.html. Accessed 10 Jan 2016

Stehfest E, Bouwman L, van Vuuren DP et al (2009) Climate benefits of changing diet. Clim Change 95:83-102

Tilman D, Clark M (2014) Global diets link environmental sustainability and human health. Nature 515:518-522. http://www. nature.com/nature/journal/v515/n7528/full/nature13959.html

Tom MS, Fischbeck PS, Hendrickson CT (2015) Energy use, blue water footprint, and greenhouse gas emissions for current food consumption patterns and dietary recommendations in the US. Environ Syst Decis. doi:10.1007/s10669-015-9577-y

U.N. Food \& Agriculture Organization (2013) FAOSTAT. http:// faostat3.fao.org/. Accessed 11 Jan 2016

U.S. Department of Agriculture (2015) USDA National Nutrient Database for Standard Reference, Release 28. http://ndb.nal. usda.gov. Accessed 11 Jan 2016 